\title{
PHYSICAL FEATURES VARIABILITY OF SPHENOID BONE ANATOMIC STRUCTURES IN ADULT
} POPULATION

Article history:

Submitted 15 March 2019

Accepted 4 June 2019

\section{Olga Aleshkina ${ }^{*}$, Tatyana Bikbaeva ${ }^{1}$, Irina Polkovova ${ }^{2}$, Marina Markeeva ${ }^{3}$, Alexey Anisimov', Olga Konnova?', Olga Fomkina ${ }^{1}$, Valeriy Konnov ${ }^{5}$}

\author{
${ }^{1}$ Human Anatomy Department, Saratov State Medical University, Saratov, \\ Russia \\ ${ }^{2}$ Department of Mobilization Training of Health and Disaster Medicine, \\ Saratov State Medical University, Saratov, Russia \\ ${ }^{3}$ Department of Otorhinolaryngology, Saratov State Medical University, \\ Saratov, Russia \\ ${ }^{4}$ Uvarovo Central District Hospital, Uvarovo, Tambov Region, Russia \\ ${ }^{5}$ Department of Orthopedic Dentistry; Saratov State Medical University, \\ Saratov, Russia
}

*Corresponding Author:aleshkina_ou@mail.ru oculomotor, the pathetic and the abducent cranial nerves [11]. The variability of the Turkish saddle shape and physical features allows one to make indirect judgment about the condition of the pituitary gland as well as about the pathological processes developing in there, in view of the fact that the average volume of the pituitary gland is $86 \%$ of the Turkish saddle volume [9]. The level of the Turkish saddle is where a bend in the skull base develops, the morphological basis of that being the basilar angle $[16,18]$. The angle size determines the type of cranial basement (plati-, medio- and flexibasilar craniotypes) affecting the structural variability of its local structures $[17,19,20]$. Given that, establishing the variation patterns in the sphenoid bone architectonics, which is part of the anterior and middle cranial fossae, involves craniometric studies taking into account the typical features of the skull structure $[3,12,15]$, since its shape variants and exact local structures dimensions generally determine the choice of surgical access to their contents $[10,13,14]$.

The data on the skull morphological variability obtained by a number of authors [3-5, 8, 21-28], are used to objectively evaluate the results of the available modern diagnostic methods, as well as to develop proper approaches and carry out radical resections with the minimal number of complications [6].

$$
\text { Aim of study: }
$$

to identify the variability of the linear parameters, the area, the Turkish saddle volume and of the sphenoid bone pituitary fossa in adults, depending on the skull base type.

\section{MATERIALS AND METHODS.}

The study was carried out on 87 registered skulls of mature age people (aged 21-60) from the scientific craniological collection of the Human Anatomy Department, V.I. Razumovsky Saratov State Medical University. The stereotopometric method, through which the device of craniosterebasiometer was used, allowed identifying the basilar angle, which in turn made it possible to detect one average and two extreme types of the skull base - mediobasilar, flexibasilar, and platibasilar [2].

Within the craniometry method, following the technique commonly employed in craniology [1], a 
technical caliper with a divide value of $0.01 \mathrm{~mm}$ was used to measure the linear parameters of the Turkish saddle and sphenoid bone pituitary fossa - the longitudinal diameter of the Turkish saddle (length), i.e. the distance from the saddle tubercle to the saddle back base and the transverse diameter (width), i.e. the distance between the most medial edges of the carotid sulci; the longitudinal diameter of the pituitary fossa - the distance between the most distant points in the sagittal plane and the transverse diameter - the distance between the most distant points in the frontal plane; the pituitary fossa depth - a perpendicular from the line drawn between the saddle tubercle and back, to the deepest point at the pituitary fossa bottom. The area and the volume of these anatomical structures of the sphenoid bone body were identified subject to the standard mathematical calculation methods.

The statistical processing of the obtained data was done using the Statistica 6.0 application software (Windows OS). For all studied parameters, the variation statistics elements were determined $-M$, $\mathrm{m}, \sigma, \mathrm{Cv} \%$, P. Since the variant distribution revealed little difference from the normal values, the statistical significance of the differences between the average values were calculated using Student's criterion. The differences were considered statistically significant at $\mathrm{p}<0.05$.

Results and discussion. In the platibasilar type, the Turkish saddle length $(14.7 \pm 0.2 \mathrm{~mm})$ was 2.0 $\mathrm{mm}$ longer than that of the medio- $(12.7 \pm 0.2 \mathrm{~mm}$; $\mathrm{P}<0.05)$, and $2.6 \mathrm{~mm}$ over that in the flexibasilar craniotypes $(12.1 \pm 0.3 \mathrm{~mm} ; \mathrm{P}<0.01)$; however, the two latter types of the skull base had no statistical difference $(\mathrm{P}>0.05)$ in this parameter. The sphenoid bone Turkish saddle length $(14.7 \pm 0.2 \mathrm{~mm})$ in the platibasilar type exceeded its width $(11.8 \pm 0.1 \mathrm{~mm}$; $\mathrm{P}<0.05)$ by $2.9 \mathrm{~mm}$, while in the medio- and flexibasilar craniotypes the width dominated $(12.7 \pm 0.2 \mathrm{~mm}$; $12.1 \pm 0.3 \mathrm{~mm})$ over length $(13.9 \pm 0.3 \mathrm{~mm} ; 14.3 \pm 0.3$ $\mathrm{mm}$; $\mathrm{P}<0.05$; $\mathrm{P}<0.01$ ) by $1.2 \mathrm{~mm}$ and $2.2 \mathrm{~mm}$, respectively.

The Turkish saddle area had the highest average value in the mediobasilar type $\left(176.53 \mathrm{~mm}^{2}\right)$ and the smallest, equal in value, in the plati- and flexibasilar $\left(173.46 \mathrm{~mm}^{2} ; 173.03 \mathrm{~mm}^{2}\right)$ craniotypes. The predominance of the Turkish saddle area in the mediobasilar type compared to the area of the plati- and flexibasilar types was by $3.07 \mathrm{~mm}^{2}$ and $3.5 \mathrm{~mm}^{2}$, respectively.

In the platibasilar type of the skull base, the width of the pituitary fossa $(10.1 \pm 0.4 \mathrm{~mm})$ was slightly above $(0.2 \mathrm{~mm})$ the length $(9.9 \pm 0.3 \mathrm{~mm} ; \mathrm{P}>0.05)$ and exceeded its depth by $3.7 \mathrm{~mm}(6.4 \pm 0.3 \mathrm{~mm} ; \mathrm{P}<0.01)$. In the mediobasilar type, the width $(10.3 \pm 0.4 \mathrm{~mm})$ prevailed over its length by $1.5 \mathrm{~mm}(8.8 \pm 0.2 \mathrm{~mm})$ and by $2.7 \mathrm{~mm}$ - over its depth $(7.6 \pm 0.3 \mathrm{~mm}$; $\mathrm{P}<0.01)$. In the flexibasilar craniotype, the fossa width $(10.8 \pm 0.4 \mathrm{~mm})$ exceeded its length $(8.7 \pm 0.2 \mathrm{~mm})$ by $2.1 \mathrm{~mm}$ and by $1.1 \mathrm{~mm}$ - its depth $(7.6 \pm 0.3 \mathrm{~mm}$; $\mathrm{P}<0.01)$.

A comparative analysis of the variability showed that in the platibasilar type the length of the pituitary fossa $(9.9 \pm 0.3 \mathrm{~mm})$ was $1.1 \mathrm{~mm}$ and $1.2 \mathrm{~mm}$ longer than that of the medio- and flexibasilar craniotypes $(8.8 \pm 0.2 \mathrm{~mm}$ and $8.7 \pm 0.2$, respectively; $\mathrm{P}<0.01)$; however, talking of the two latter skull base types, this parameter was observed to feature no significant differences $(\mathrm{P}>0.05)$. The average pituitary fossa width of each craniotype did not have significant differences and ranged from $10.1 \pm 0.4 \mathrm{~mm}$ for the platibasilar to $10.8 \pm 0.4 \mathrm{~mm}$ for the flexibasilar craniotypes $(\mathrm{P}>0.05)$. The average depth of the fossae in the medio- and flexibasilar craniotypes was equally variable $(7.6 \pm 0.3 \mathrm{~mm}$; $\mathrm{P}>0.05)$ and the value of this parameter in the platibasilar type prevailed by $1.2 \mathrm{~mm}(\mathrm{P}<0.05)$.

The highest average value of the pituitary fossa area was in the platibasilar type and was $78.53 \mathrm{~mm}^{2}$, whereas the lowest value was in the medio- and flexibasilar $\left(71.18 \mathrm{~mm}^{2} ; 73.79 \mathrm{~mm}^{2}\right)$ craniotypes. The predominance of the pituitary fossa area in the platibasilar type compared with the respective area in the medio- and flexibasilar fossae was $7.35 \mathrm{~mm}^{2}$ and $4.74 \mathrm{~mm}^{2}$, respectively.

In the flexibasilar type, the pituitary fossa volume was on average $373.8 \mathrm{~mm}^{3}$; in the medio- and platibasilar craniotypes - $360.68 \mathrm{~mm}^{3}$ and $261.79 \mathrm{~mm}^{3}$, respectively. The biggest volume difference between the flexi- and platibasilar types was $112.11 \mathrm{~mm}^{3}$, between the plati- and the mediobasilar types - $98.89 \mathrm{~mm}^{3}$, while it was the lowest between the flexi- and mediobasilar types $-13.22 \mathrm{~mm}^{3}$.

The longitudinal diameter of the Turkish saddle, as our research showed, ranged on average from $12.1 \pm 0.3 \mathrm{~mm}$ (flexibasilar craniotype) to $14.7 \pm 0.2$ $\mathrm{mm}$ (platibasilar craniotype), transverse - from $11.8 \pm 0.1 \mathrm{~mm}$ (platibasilar craniotype) to $14.3 \pm 0.3 \mathrm{~mm}$ (flexibasilar craniotype). The longitudinal diameter variability range of the pituitary fossa, depending on the skull base type, was from $8.7 \pm 0.2 \mathrm{~mm}$ (flexibasilar craniotype) to $9.9 \pm 0.3 \mathrm{~mm}$ (platibasilar craniotype); depth - from $6.4 \pm 0.3 \mathrm{~mm}$ (platibasilar craniotype) to $7.6 \pm 0.3 \mathrm{~mm}$ (medio- and flexibasilar craniotypes), while the transverse diameter did not have typical variability and averaged $10.1-10.8 \pm 0.4 \mathrm{~mm}$. The available literature offers data supplied by a number of authors regarding the average values of the dimensional specifics of the sphenoid bone structure in adults, the Turkish saddle: longitudinal size $-11.6 \mathrm{~mm}$, 
$14.0 \mathrm{~mm}$; transverse $-14.5 \mathrm{~mm}$; vertical $-8.5 \mathrm{~mm}$, $12.0 \mathrm{~mm}$; pituitary fossa - length $-12.0 \mathrm{~mm}$, width $-13.0 \mathrm{~mm}$, height $-3.5 \mathrm{~mm}[3,7,8]$, however comparison is not possible due to difference in the research methodologies.

As our study revealed the pituitary fossa in the platibasilar type is rounded, small, with an area of 78.5 $\mathrm{mm}^{2}$, whereas in the medio- and flexibasilar craniotypes it is oval-shaped, deep, with an area of $71.2 \mathrm{~mm}^{2}$ and $73.8 \mathrm{~mm}^{2}$, respectively, which cannot be matched against the data from V.S. Maikova-Stroganova and D.G. Rokhlin [8], who, using only the correlation of vertical and sagittal dimensions, ponted at flat, round and deep types of shape. The pituitary fossa area predominated in the platibasilar type by $7.4 \mathrm{~mm}^{2} \mathrm{com}$ pared with the medio- and $4.7 \mathrm{~mm}^{2}$ compared with the flexibasilar craniotype.

\section{CONCLUSION}

The above means that the highest prevalence of the Turkish saddle area in comparison with the pituitary fossa area was $105.3 \mathrm{~mm}^{2}$ for the mediobasilar type (occupies $40.3 \%$ of the area of the saddle); the lowest ratio for the platibasilar type was $95.0 \mathrm{~mm}^{2}$ ( $45.2 \%$ of the saddle area), whereas for the flexibasilar type, the Turkish saddle area was $99.6 \mathrm{~mm}^{2}$ above the fossa area ( $42.4 \%$ of the saddle area). A typical variability of the linear parameters of the sphenoid bone body structures, determining their configuration, was identified - the platibasilar type of the skull base features a long and narrow Turkish saddle, a small and round pituitary fossa, with a larger area and a smaller volume. For the medio- and flexibasilar craniotypes, the Turkish saddle is short and wide; the pituitary fossa is deep, oval-shaped with a smaller area, yet with a large volume. There has been no typical variability for the Turkish saddle area revealed.

\section{REFERENCES}

1. Alekseev V.P., Debets G.F. Craniometry. Methods of anthropological research. - M .: Science. - 1964. 128 p. (In Russ.).

2. Aleshinina O.Yu., Nikolenko V.N. Bazykranialny typology of human skull construction Moscow. - 2014. - 160 p. https://elibrary.ru/item. asp?id $=22424954$

3. Gaivoronsky I.V., Yakovlev A.A. Variant anatomy and morphometric characteristics of the sphenoid bone of an adult // Bulletin of the Russian Military Medical Academy. - 2011. - № 3 (35). - P. 146-150. https://elibrary.ru/item.asp?id=17018976

4. Aleshina O.Yu., Nikolenko V.N., Zaichenko A.A. Typology of the skull depending on the individual variability of the basilar angle // Morphological statements. - 2001. - № 3-4. - P. 14-15. https://elibrary. $\mathrm{ru} / \mathrm{item}$. asp?id=20207617
5. Morphostereotopometric variability and spatial arrangement of the ethmoid structures in adults / O.Yu. Aleshkina, M.V. Markeeva, O.V. Mareev, TS Bikbaeva, I.A. Polkovova // News of higher educational institutions. Volga region. Medical sciences. -2017 . -№ 3 (43). - P. 5-12. DOI: 10.21685/2072-3032-2017-3-1

6. Endoscopic endonasal surgery of pituitary adenomas (experience of 1700 operations) / P.L. Kalinin, D.V. Fomichev, M.A. Kutin et al. / / Journal of Neurocirculation Problems. Academician N.N. Burdenko. - 2012. - № 3. - P. 26-33. https://elibrary.ru/item. asp?id $=18000698$

7. KoveSHNikov V.G. On the question of the variability of the form of the Turkish saddle // Proceedings of the Saratov Medical Institute. - 1960. - T. 31 (48). - P. $-92-95$.

8. MaYkova-Stroganov B.C., Rokhlin D.G. Bones and joints in the $\mathrm{x}$-ray image. Head. - L .: Medgiz. 1955. Vol. 3. - 476 p.

9. The ratio between the pituitary and the volume of the Turkish saddle / LA. Pikulev, S.M. Gerasimov, V.M. Cheremisin, V.M. Shipilov // Archive of Anatomy. 1970. - №9. - P. 98-104.

10. Typical variability of the pterygo-maxillary fissure depending on the shape of the facial skull / I.A. Polkovova, O. Yu. Aleshkina, V.N. Nikolenko, E.V. Chernyshkova, TS Bikbaeva // Morphological statements. - 2017. - T. 25. - № 2. - P. 57-59. https://elibrary.ru/ item.asp?id $=29426540$

11. Fomichev D.V. Endoscopic endonasal removal of pituitary adenomas (anatomical rationale, methods of operations and immediate results): author. dis.... Cand honey. sciences. - M. - 2007. - 25 p. https://elibrary.ru/ item.asp?id $=30321482$

12. Variability of linear parameters of cranial pits of the inner base of the skull depending on craniotype / O.Y. Aleshkina, V.N. Nikolenko, Yu.A. Khurchak, A.N. Anisimov, TS Bikbaeva, I.A. Polkovova // Morphology. - 2018. - T. 153. - № 3. - P. 16.

13. Aleshina O.Yu., Polkovova I.A., Bikbaeva TS Age and sexual variability of the dimensional characteristics of the openings of the outer base of the skull // Morphology. - 2018. - T. 153. - № 3. - P. 15-16.

14. Virtual craniometry as a new method in craniology / O.V. Mareev, V.N. Nikolenko, G.O. Mareev, O. Yu. Aleshkina, M.V. Markeeva, V.N. Kuchmin, N.M. Yakovlev, M.E. Geivondian // Perspectives on Science. - 2014. - № 7 (58). - P. 10-14.

15. Comparative characteristics of linear and angular parameters of the anterior cranial fossa at the extreme types of the skull base / O.Yu. Aleshkina, Yu.A. Khurchak, D.N. Rossoshansky, A.N. Anisimov // Astrakhan Medical Journal. - 2013. - V. 8. - № 1. - P. 29-31.

16. Aleshrina O.Yu., Aleshrina I.A. The variability of the angles of the base of the human skull and their relationship // Morphological statements. - 2004. - № 112. - P. 5. 
17. Stereotopometry of the trabecular and parachordal parts of the human cranial skull / V.S. Speransky, A.A. Zaichenko, O. Yu. Aleshkina, E.A. Anisimova // Morphology. - 1997. - T. 112. - № 5. - P. 81.

18. Variability of the angle of curvature of the base of the skull and the orientation of the plane of the large hole / O.Yu. Aleshkina., VS. Speransky, L.V. Muzurova, A.A. Zaichenko, E.A. Anisimova // Russian morphological statements. - 1999. - № 1-2. - P. 140.

19. Typology of the human cranial skull from the standpoint of phylogenesis and ontogenesis / V.N. Nikolenko, O. Yu. Aleshkina, A.A. Zaichenko., E.A. Anisimova // Morphology. - 2002. - T. 121. - № 2-3. P. 38.

20. Aleshinina O. Yu. Extreme types of the shape of the base of the human skull / Morphological statements. 2003. - № 1-2. - P. 8.

21. Variability of human cerebral hemispheres temporal operculum / Yu.A. Gladilin, O.A. Fomkina, L.V. Muzurova, E.A. Anisimova, O.Yu. Aleshkina, R.M. Khairullin, O.V. Syrova, V.V. Konnov // Archiv EuroMedica. - 2019. - T. 9; 1. - C. 26-29. https://doi. org/10.35630/2199-885X/2019/9/1/26

22. Morphofunctional changes in temporomandibular joint correlating with its morphological variations in patients with dentition defects complicated by distal occlusion / V.V. Konnov, A.P. Vedyaeva, D.Kh. Razakov, E.N. Pichugina, T.V. Matytsina, S.N. Salnikova, M.V. Vorobeva, R.N. Mukhamedov, I.V. Matysina // Archiv EuroMedica. - 2019. - Vol. 9; 1. - P. 52-58. https://doi.org/10.35630/2199-885X/2019/9/1/52

23. Specific features of major angular parameters of cranio-facial complex in males and females with mesial occlusion in their first mature age / L.V. Muzurova, E.A. Anisimova, O.A. Fomkina, Yu.A. Gladilin, A.A. Zaychenko, T.M. Zagorovskaya, R.M. Khairullin, V.V. Konnov // Archiv EuroMedica. - 2019. - Vol. 9; 1. - P. 66-68. https://doi.org/10.35630/2199$885 \mathrm{X} / 2019 / 9 / 1 / 66$

24. Temporomandibular joint morphology at orthognatic bite / A.R. Arushanyan, V.V. Konnov, A.P. Vedyaeva, D.Kh. Razakov, T.V. Matytsina, D.N. Maslennikov, R.N. Mukhamedov, A.S. Khodorich, I.V. Matysina // Archiv EuroMedica. - 2019. - Vol. 9; 1. - P. 18-19. https://doi.org/10.35630/2199-885X/2019/9/1/18

25. DMitrienko S.V., Davydov B.N., V.V. SHKarin, DoMENYuK D.A. Algorithm for determining the size of artificial teeth by the morphometric parameters of the face in people with full adentia. Dentistry. 2018; 97(6): 57-60. DOI - 10.17116/stomat20189706157

26. KorobkeEv A.A., Domenyuk D.A., ShKarin V.V., DMitrienko S.V. Types of facial heart depth in physiological occlusion. Medical news of North Caucasus. 2018. - Vol. 13. - № 4. - P. 627-630. (In Russ., English abstract). DOI - https://doi.org/10.14300/ mnnc.2018.13122

27. Dmitrienko T.D., Domenyuk D.A., Porfyriadis M.P., Arutyunova A.G., Kondratyuk A.A., Subbotin R.S. Connection between clini- cal and radiological torque of medial incisors at physiological occlusion. Archiv Euro Medica, 2019; Vol. 9; 1: 29-37. https://doi.org/10.35630/2199$885 \mathrm{X} / 2019 / 9 / 1 / 29$

28. Dmitrienko S.V., Fomin I.V., Domenyuk D.A., Kondratyuk A.A., SubBotin R.S. Enhancement of research method for spatial location of temporomandibular elements and maxillary and mandibular medial incisors. Archiv Euro Medica, 2019; Vol. 9; 1: 38-44. https://doi.org/10.35630/2199$885 \mathrm{X} / 2019 / 9 / 1 / 38$ 